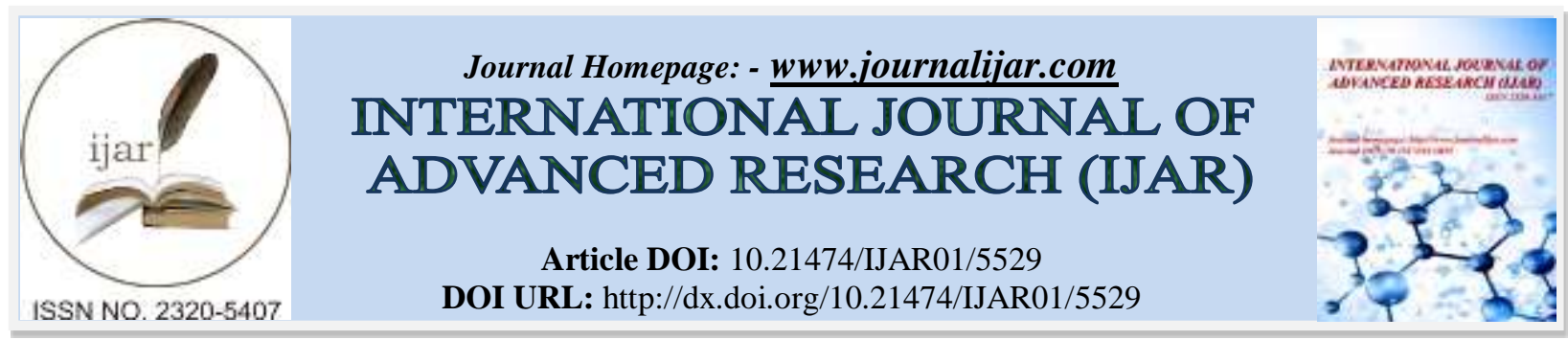

RESEARCH ARTICLE

\title{
TWO STEP TRANSFER OF RYE-DERIVED HESSIAN FLY- RESISTANCE GENE H21 TO DURUM WHEAT BY COMPENSATING ROBERTSONIAN TRANSLOCATION AND INDUCED HOMOEOLOGOUS RECOMBINATION.
}

\author{
Moha Ferrahi ${ }^{1}$, B. Friebe ${ }^{2}$, J. H. Hatchett ${ }^{3}$, G. L. Brown-Guedira ${ }^{4}$ and B. S. Gill ${ }^{2}$.
}

1. Moha Ferrahi, National Institute for Agricultural Research, Regional Center of Meknes, BP 578, Meknes, Morocco 50000.

2. B. Friebe and B.S. Gill, Dept. Of Plant Pathology, Wheat Genetics Resource Center, Throckmorton Plant Sciences Center, Kansas State University, Manhattan, KS 66506-5502, USA.

3. J.H. Hatchett, Dept. of Entomology and USDA-ARS, Waters Hall, Kansas State University, Manhattan, KS 66506-5502, USA.

4. G.L. Brown-Guedira, Dept. Of Agronomy and USDA-ARS, Throckmorton Plant Sciences Center, Kansas State University, Manhattan, KS 66506-5502, USA.

\section{Manuscript Info}

Manuscript History

Received: 03 August 2017

Final Accepted: 05 September 2017

Published: October 2017

Key words:-

Triticum turgidum, Secale cereale, Hessian fly, wheat-rye translocation, induced homoeologous recombination.

\begin{abstract}
The Hessian fly resistance gene $H 21$ is present on the wheat-rye wholearm translocation T2BS·2RL and was recently transferred to durum wheat. However, homozygous lines for this translocation have poor plant vigor, low seed set, and are almost completely sterile, making it impossible to use this germplasm directly in durum wheat improvement. The objective of this study was to reduce the rye segment in T2BS·2RL using $p h$-mediated recombination, thereby making this gene available for durum breeding. A total of 39 primary recombinants from a population of 512 plants $(7.6 \%)$ were recovered involving $10 \%$ of the distal segment of the long arm of rye or wheat. Among these primary recombinants 21 (53.8\%) had distal rye chromatin, $12(30.8 \%)$ had distal wheat chromatin, the remaining four had either very distal wheat or rye and two were interstitial recombinants. Ten out of 39 primary recombinants were tested for their resistance to Hessian fly. Three recombinants (Rec. \# 1, 2,3) with about the distal $10 \%$ of $2 \mathrm{BL}$ arm derived from rye reacted resistant and, thus, had the $H 21$ gene. Two recombinants (Rec. \# 4, 5) with very distal rye chromatin reacted susceptible to the Hessian fly. Three other primary recombinants (Rec. \# 6, 7,8) with the distal $10 \%$ of the $2 \mathrm{RL}$ arm derived from wheat were susceptible to Hessian fly and did not retain the $H 21$ gene. The remaining two recombinants (Rec. \# 9, 10) with very distal wheat segments were resistant and still had the resistance gene $H 21$. The distal primary recombinants with the gene were vigorous and had normal seed set and can now be used in the improvement of durum wheat.
\end{abstract}

Copy Right, IJAR, 2017,. All rights reserved. 


\section{Introduction:-}

The Hessian fly, Mayetiola destructor (Say), is a major insect pest of wheat. Genetic resistance is the most effective and economical means of controlling this insect (Ratcliffe and Hatchett 1997). To date, 29 Hessian fly-resistance genes ( $H 1$ through $H 29$ ) have been identified in Triticum/Aegilops species and in Secale cereale L. (McIntosh et al., 1998). The mechanism of resistance conditioned by these genes is antibiosis, whereby first instars die soon after they begin to feed on plants. A gene-for-gene relationship exists between the resistance in wheat and avirulence in the Hessian fly. Virulence in the insect is conditioned by homozygous recessive pairs of genes (Hatchett and Gallun 1970). As a consequence of this highly specific interaction, 16 biotypes (designated Great Plains and A through O) have been isolated from field populations and are distinguished only by their ability or inability to survive on and stunt wheat with specific resistance genes.

Triticum Turgidum L. is an important crop in the Mediterranean region and is grown on approximately 17 millions hectares. Lacking adequate levels of resistance, this crop usually is damaged severely by Hessian fly in the dry areas of northern Africa. In Morocco, yield losses due to damage by this insect have been estimated at up to $36 \%$ of the yearly small grain production (Lhaloui et al. 1998). Among the identified genes for resistance to Hessian fly, ten have been found to be effective against the Moroccan populations of the insect and have been widely used in cultivar development of bread wheat (El Bouhssini et al. 1998). However, only one source of resistance was identified in durum wheat.

Recently, the rye-derived Hessian fly gene $H 21$ was transferred to durum wheat (Friebe et al., 1999). The Hessian fly resistance gene $H 21$ was derived from 'Chaupon' rye and first transferred to bread wheat (Triticum aestivum L.) in the form of a Robertsonian wheat-rye T2BS·2RL translocation using tissue culture (Friebe et al. 1990). Homozygous $H 21$ durum plants have poor plant vigor and are almost completely sterile. Here we report the $2^{\text {nd }}$ step of chromosome manipulation, aimed to shorten the rye segment in T2BS·2RL by induced homoeologous recombination (Friebe et al. 1994; Jiang et al. 1994b).

\section{Material and methods:-}

The plant material used in this study consisted of the $H 21$ durum germplasm (Friebe et al., 1999), the phlc Cappelli mutant (Giorgi, 1978) and the Langdon 5D(5B) disomic substitution lines where chromosome pair 5B is missing and replaced by a pair of 5D chromosomes (Joppa, 1993). All lines are maintained at the Wheat Genetics Resource Center at Kansas State University, Manhattan.

Durum plants heterozygous for the translocation T2BS·2RL were crossed to Cappelli ph mutant (Figure 1a) and Langdon $5 \mathrm{D}(5 \mathrm{~B})$ substitution lines (Figure $1 \mathrm{~b}$ ) during the autumn 1998. In the first crossing scheme, $\mathrm{F}_{1}$ lines were germinated and plants with $13 "$ + T2BS·2RL' + 2B' (Phlc phlc) were selected by C-banding and backcrossed to Cappelli phlcphlc mutant. The resulting $\mathrm{BC}_{1} \mathrm{~F}_{1}$ plants with the chromosome constitution $13 "+\mathrm{T} 2 \mathrm{BS} \cdot 2 \mathrm{RL}{ }^{\prime}+2 \mathrm{~B}^{\prime}$ (phlc phlc) was backcrossed to Cappelli phlc to produce $\mathrm{BC}_{2} \mathrm{~F}_{1}$ and selfed to produce $\mathrm{BC}_{1} \mathrm{~F}_{2}$. The screening for (phlc, phlc) plants was accomplished first by screening for the translocation by C-banding and then using PCR marker PSR574 developed by Roberts et al. (1999) specific to the Phl locus. The primers were PSR574.f 5'-AGC GTA TAT TCA CGC GCT CC and PSR574.r 5'-CGT AAG AAC TCC CCA GGC TTT G. This was tested only in few individuals, as the number of crosses carried out was high. We used mostly plants screened only by $\mathrm{C}$-banding to advance lines to the next generation. In the second crossing scheme, the $\mathrm{F}_{1}$ lines were germinated and plants with the chromosome constitution $12 "$ + T2BS·2RL' + 2B' + 1'5B + 1'5D were selected by C-banding then backcrossed to Langdon $5 \mathrm{D}(5 \mathrm{~B})$. The resulting $\mathrm{BC}_{1} \mathrm{~F}_{1}$ plants with the chromosome constitution $12^{\prime \prime}+\mathrm{T} 2 \mathrm{BS} \cdot 2 \mathrm{RL}+2 \mathrm{~B}^{\prime}+1{ }^{\prime \prime} 5 \mathrm{D}$ were backcrossed to Langdon $5 \mathrm{D}(5 \mathrm{~B})$ to produce $\mathrm{BC}_{2} \mathrm{~F}_{1}$ and selfed to produce $\mathrm{BC}_{1} \mathrm{~F}_{2}$.

Recombinants were selected in the $\mathrm{BC}_{1} \mathrm{~F}_{2}$ and $\mathrm{BC}_{2} \mathrm{~F}_{1}$ populations. Chromosome identification during the course of line selection was according to the standard C-banding protocol described by Gill et al. (1991) and Genomic In Situ Hybridization (GISH) was according to Jiang et al. (1994a). Meiotic metaphase I pairing was analyzed in the pollen mother cells (PMCs) in $\mathrm{BC}_{1} \mathrm{~F}_{2}$ and $\mathrm{BC}_{2} \mathrm{~F}_{1}$ plants using GISH.

Evaluation of resistance to Hessian fly was according to Hatchett et al. (1981) and Friebe et al. (1990). Plants in the seedling stage were evaluated for their reaction to biotype L of the Hessian fly. Biotype $\mathrm{L}$ is the most virulent biotype presently found in the field. Greenhouse temperature was maintained between $18^{\circ} \mathrm{C}$ and $24^{\circ} \mathrm{C}$ throughout the tests. Adult Hessian flies were allowed to oviposit for 8 hours on plants in the one- to two-leaf stage. Plants were examined after oviposition, and all were found to be infested with large numbers of eggs on the first leaf. 
Susceptible and resistant plant reactions were determined 15 days after egg infestation. The susceptible plants are stunted and dark green, whereas the resistant plants are normal in color and were examined for dead larvae to confirm resistance.

\section{Results:-}

\section{GISH analysis:-}

Durum plants heterozygous for T2BS·2RL were crossed with Cappelli phllc/phlc and the Langdon 5D(5B) substitution line, and a total of $512 \mathrm{BC}_{1} \mathrm{~F}_{2}$ and $\mathrm{BC}_{2} \mathrm{~F}_{1}$ plants were screened by GISH for primary recombinants. Thirty-nine wheat-rye recombinants were identified (Table 1), and the majority had crossovers that mapped in the distal region of the $2 \mathrm{RL}$ of $\mathrm{T} 2 \mathrm{BS} \cdot 2 \mathrm{RL}$ and $2 \mathrm{BL}$ of wheat chromosome $2 \mathrm{~B}$.

The results in Table 1 indicate that out of 39 recovered translocations, $21(54 \%)$ were in the form of T2BS-2BL-2RL with about $10 \%$ of the distal part long arm 2BL derived from rye chromatin (Figures 2d, 2e and 2f). Twelve translocations (31\%) were in the form of T2BS·2RL-2BL with about $10 \%$ of the distal part long arm 2RL derived from wheat (Figures $2 \mathrm{i}, 2 \mathrm{j}$ and $2 \mathrm{k}$ ). Two translocations (5\%) had very small rye segments in the distal part of long arm 2BL (Figures $2 \mathrm{~g}, 2 \mathrm{~h}$ ), and two translocations had very small wheat segments in the distal part of long arm 2RL (Figures 21, 2m).

Other types of recombinants also were obtained. For one translocation, T2BS·2RL-2BL, nearly the entire distal half of the chromosome arm is rye and the proximal half is wheat (Figure not shown). The reciprocal translocation, T2BS·2BL-2RL, in which the distal half is wheat and proximal half is rye (Figure not shown), also was recovered. One plant was identified with isochromosome 2RL (Figure not shown) that originated from misdivision of chromosome T2BS·2RL.

\section{Pairing analysis and recombination frequency:-}

Meiotic metaphase I pairing data was recorded in $\mathrm{BC}_{1} \mathrm{~F}_{2}$ and $\mathrm{BC}_{2} \mathrm{~F}_{1}$ plants. In 10 PMCs chromosomes T2BS.2RL and $2 \mathrm{~B}$ paired as ring bivalents $(6.7 \%)$, in $130 \mathrm{PMCs}(86.6 \%)$ they paired as rod bivalents with chiasmata formed in the homologous 2BS arms, and in 10 PMCs (6.7\%) they were univalent (Table 2).

Among 512 plants screened, 142 plants had the T2BS·2RL translocation chromosome indicating a transmission frequency of $27.7 \%$. Thirty-nine primary recombinants were identified, which corresponds to a recombination frequency of $7.6 \%$. The Cappelli $p h$ mutant-derived crosses gave higher transmission frequency $(30.7 \%)$ and lower recombination frequency $(6.9 \%)$ when compared to Langdon $5 \mathrm{D}(5 \mathrm{~B})$, which gave a lower transmission $(24.6 \%)$ and higher recombination frequency $(8.3 \%)$ (Table 3). The difference in transmission frequency is statistically significant at $\mathrm{P} \leq 0.05$, however the difference in recombination frequency is not statistically significant.

Figure 2 shows the meiotic metaphase I pairing of the translocation chromosome T2BS.2RL and derived recombinants and GISH patterns of some of the primary recombinants recovered in this experiment. In the presence of Phl, T2BS·2RL paired with 2B in the homologous 2BS arm as a rod bivalent (Figure 2a). In the absence of Phl, T2BS.2RL paired with chromosome 2B as a ring bivalent (Figure 2b), and the homoeologous pairing occurred between $2 \mathrm{RL}$ and $2 \mathrm{BL}$. Figure 2c shows the meiotic metaphase I pairing of one homozygous primary recombinant that paired in the form of ring bivalent.

\section{Hessian fly testing of recombinants:-}

Ten of the primary recombinants were evaluated for their resistance to Hessian fly. Thirteen plants of each recombinant were grown and root tips were collected and analyzed by GISH in parallel with the Hessian fly testing. Three recombinants with distal rye segments (T2BS·2BL-2RL) designated as rec. \#1, rec. \#2, and rec. \#3 were resistant and, thus, contain the gene $H 21$ (Figures 2d, 2e and 2f). We can map the $H 21$ in the distal 10\% of 2RL. Hessian fly testing also indicated that for the translocation T2BS-2RL-2BL, three recombinants designated as rec. $\# 6$, rec. \#7 and rec. \#8, were susceptible and lacked $H 21$ (Figures $2 \mathrm{i}, 2 \mathrm{j}$ and $2 \mathrm{k}$ ).

The Hessian fly testing of the other types of recovered recombinants showed that rec.\#4 and rec.\#5 (Figures $2 \mathrm{~g}$ and $2 \mathrm{~h}$ ), which are in the form of T2BS·2BL-2RL, were susceptible to the insect and did not have the $H 21$ gene. The recombinants rec.\#9 and rec. \#10 (Figures 21 and $2 \mathrm{~m}$ ) had a wheat segment in the distal part of rye long arm 2RL (T2BS·2RL-2BL) and reacted resistant to the insect and still retain the H21. Such recombination events are not of agronomic interest because they still retain a nearly complete $2 \mathrm{RL}$ arm that has deleterious effects. 
Plants homozygous for T2BS·2BL-2RL that expressed $H 21$ but only had approximately $10 \%$ of the $2 \mathrm{RL}$ arm were obtained that are vigorous and fully fertile. This germplasm will allow us to exploit $\mathrm{H} 2 \mathrm{I}$ in durum wheat improvement.

\section{Discussion:-}

Successful gene transfers from alien species rely on the ability of the chromosomes to recombine with homoeologous wheat chromosomes. In wheat, chromosome pairing is restricted to homologous chromosomes, which is controlled by the Phl locus on chromosome arm 5BL (Okamoto 1975; Riley and Chapman 1958). Two deletions in this locus have been identified, one in hexaploid wheat (phlb, Sears 1977) and the other in tetraploid wheat (phlc, Giorgi 1978). Riley and co-workers (1968a, b) were the first to use induced homoeologous recombination to transfer genes conferring resistance to stripe rust $(\mathrm{Yr} 8)$ and stem rust ( $\mathrm{Sr} 34)$ from Aegilops comosa Sibth. And Smith $(2 \mathrm{n}=2 \mathrm{x}=14, \mathrm{MM})$ to wheat.

Although a considerable number of successful alien introgressions involving homoeologous chromosome segments have been achieved in hexaploid wheat (for review see Sears 1993; Friebe et al. 1996; Lukaszewski 2000). Very little progress has been made in durum wheat (Dvorak and Gorham 1992; Dvorak et al. 1994; Luo et al. 1996b; Ceoloni et al. 1996), probably because the buffering ability of tetraploid durum wheat is less than that of hexaploid wheat. Other sources of resistance need to be used in durum wheat improvement to increase the genetic variability. Aegilops tauschii (Coss.) Schmal. $(2 \mathrm{n}=2 \mathrm{x}=14, \mathrm{DD})$ and rye (Secale cereale, $\mathrm{RR})$ are good sources of resistance to all known biotypes of the insect. Ae. tauschii is the source of five genes $(H 13, H 22, H 23, H 24$, and H26), and rye is the source of two genes ( $H 21$ and $H 25$ ).

In this study primary recombinants were recovered as a result of homoeologous recombination between wheat and rye chromosome arms. Several previous studies have reported that the long arms of rye chromosomes $1 \mathrm{R}$ and $2 \mathrm{R}$ pair relatively frequently with their wheat homoeologous (Naranjo and Fernandez-Rueda 1996; Lukaszewski 1993, 1997 and 2000). In the present study, chiasmate metaphase I association between the 2RL arm of rye and the 2BL of wheat was $6.7 \%$, which corresponds with the number of primary recombinants identified in $\mathrm{BC}_{1} \mathrm{~F}_{2}$ and $\mathrm{BC}_{2} \mathrm{~F}_{1}$ plants (7.6\%) and previous published data (Lukaszewski 1993,1997 and 2000; Naranjo and Fernandez-Rueda 1996). The observed recombination frequency of $2 \mathrm{RL}$ with $2 \mathrm{BL}$ was close to that expected on the basis of their MI pairing frequency in the absence of Phl (Naranjo and Fernandez-Rueda 1996). Dvorak and Lukaszewski (2000) have reported a recombination frequency of $8.1 \%$ between $2 \mathrm{RL}$ and $2 \mathrm{BL}$ in the absence of $P h l$ after testing 860 progeny chromosomes and no recombination of 2RL with any of its wheat homoeologs was observed in the presence of Phl. Lukaszewski (2000) showed that chromosome arm 2RL in T2BS·2RL when induced to recombine with 2BL did so with about $8 \%$ frequency and almost $90 \%$ of the recombination events involved $2 \mathrm{BL}$, whereas $2 \mathrm{RS}$ recombined with 2BS only with a frequency of $0.2 \%$. On the other hand chromosome arms, $1 \mathrm{RS}$ and $2 \mathrm{RS}$, which pair with their wheat homoeologous at lower frequencies, show a much lower frequency of recombination and often recombine with the non-homoeologous arms (Lukaszewski 2000). RFLP analysis indicated that the 2RL arm is not structurally rearranged compared with group-2 long arms of wheat (Devos et al. 1993). The 2RL arm is expected to compensate well and recombine more often with wheat chromosome arm 2BL.

Several authors have reported a seasonal variation in homoeologous recombination frequency that could affect the fidelity of $2 \mathrm{RS}$ recombination. In a season where the overall recombination is very low, non-homoeologous recombination increased significantly.

The distribution of recombination crossovers observed in this study is characteristic of transfers derived from induced homoeologous recombination. We observed a larger number of breakpoints in the distal region of the 2RL and $2 \mathrm{BL}$ arms and the absence of multiple crossovers. Out of 39 recovered primary recombinants, only two had breakpoints in the middle of the arm. Gill and Gill (1994) reported from information provided by cytogenetic ladder maps that many genes in wheat are present in clusters that are highly recombinogenic and are mostly restricted to distal part of the chromosome, which make them amenable to cloning by chromosome walking. Lukaszewski (1995) reported similar results when studying the physical distribution of translocation breakpoints in homoeologous recombinants induced by the absence of the Phl gene in wheat and triticale. Dvorak and Gorham (1992) also reported similar recombination frequencies between $4 \mathrm{D}-4 \mathrm{~B}$ when transferring the $\mathrm{K}^{+} / \mathrm{Na}^{+}$-selectivity gene Knal from Triticum aestivum into T. Turgidum in the absence of Phl. 
Chromosome pairing frequency was higher in crosses with Langdon 5D(5B) substitution lines, which lack the entire chromosome 5B (Table 2), compared to the crosses with the Cappelli phlc mutant, although in both cases the Phl gene was absent. The phlc had less pairing affinity despite the presence of $5 \mathrm{~B}$, which has a pairing promoter in the short arm (Sears, 1976). Similar results were reported by Jauhar et al. (1999). This situation is in contrast to in hexaploid wheat where chromosome pairing was higher in the phlb mutant than in nullisomic 5B (Jauhar et al. 1991; Kimber and Riley, 1963). Chromosome 5D does not seem to alter the pairing affinity in substitution lines. Chromosome 5B almost entirely controls the pairing in durum wheat and other pairing-control genes on the other chromosomes, if any, have minor effects that are too low to be noticeable in the presence of the major controller. Possibly, more than Phl locus on chromosome 5B controls pairing because pairing frequency is higher in the absence of 5B than in the presence of the phlc mutation.

The present study supports the strategy for transferring alien genes to wheat with non-homologous genomes proposed earlier by Friebe et al. (1994) and Jiang et al. (1994b). This strategy involves the development of amphiploids followed by the production of sets of chromosome addition and substitution lines, which are necessary tools for the successful gene transfer and can be used as bridge materials to generate wheat-alien chromosome translocations. The next step is the production of genetically compensating whole arm translocations and several of such compensating wheat-rye translocations are available (Friebe et al., 1996). The second step of such transfers can be accomplished either by homologous recombination to stack more genes in the alien chromosome arm as was done by Friebe et al. (1994) in transferring the powdery mildew gene Pm20 from 6RL to the existing translocation T6BS.6RL. In the case of non-homologous arms the reduction of the alien segment can be accomplished by induced homoeologous recombination as was shown in this study.

In the present study, durum wheat germplasm lines heterozygous or homozygous for the new translocation (with about only $10 \%$ of the arm as rye chromatin) were recovered that express $H 21$ resistance to Hessian fly. These recombinants have good plant vigor and set seed similar to the durum wheat parent. These germplasms can be used directly in durum wheat breeding programs.

\section{Acknowledgements:-}

This research was supported in part by a USDA-ARS special grant to the Wheat Genetics Resource Center and by a grant from Kansas Wheat Commission. We thank J. Raupp and D. Wilson for their excellent technical assistance.

Table 1:- Primary wheat-rye recombinants identified by GISH analysis.

\begin{tabular}{|l|l|l|}
\hline Recombinant type & Cross-over localization & Recombinant \\
\hline T2BS·2BL-2RL & distal & 21 \\
\hline T2BS·2RL-2BL & distal & 12 \\
\hline T2BS·2BL-2RL & interstitial & 1 \\
\hline T2BS·2RL-2BL & interstitial & 1 \\
\hline T2BS·2BL-2RL & proximal & 2 \\
\hline T2BS·2RL-2BL & proximal & 2 \\
\hline Total & & 39 \\
\hline
\end{tabular}

Table 2:- Meiotic metaphase I pairing in $\mathrm{BC}_{1} \mathrm{~F}_{2}$ and $\mathrm{BC}_{2} \mathrm{~F}_{1}$ plants between wheat chromosome $2 \mathrm{~B}$ and the wheat-rye translocation chromosome T2BS·2RL in the absence of $P h l$ gene.

\begin{tabular}{|c|l|l|l|}
\hline Total PMCs & Ring bivalent & $\begin{array}{l}\text { Pairing type } \\
\text { Rod bivalent paired in the 2BS arm }\end{array}$ & Univalent \\
\hline & & & \\
\hline 150 & 10 & 130 & 10 \\
\hline & $6.7 \%$ & $86.6 \%$ & $6.7 \%$ \\
\hline
\end{tabular}

Table 3:- Transmission frequencies of T2BS·2RL and number of recombinants identified in $\mathrm{BC}_{1} \mathrm{~F}_{2}$ and $\mathrm{BC}_{2} \mathrm{~F}_{1}$ plants in different durum wheat backgrounds.

\begin{tabular}{|c|l|l|l|l|}
\hline Number of plants & $\begin{array}{l}\text { Genetic } \\
\text { constitution }\end{array}$ & $\begin{array}{l}\text { Plants } \\
\text { T2BS·2RL }\end{array}$ & $\begin{array}{l}\text { Number } \\
\text { recombinants }\end{array}$ \\
\hline & $\begin{array}{l}\text { Cappelli phlc } \\
260\end{array}$ & $\begin{array}{l}133^{\prime}+ \\
\text { T2BS·2RL'+1' }\end{array}$ & $80(30.7 \%) \mathrm{a}$ & $18(6.9 \%) \mathrm{a}$ \\
\hline
\end{tabular}




\begin{tabular}{|l|l|l|l|l|}
\hline & & 2B (phlcphlc) & & \\
\hline & $\begin{array}{l}\text { LND 5D(5B) } \\
252\end{array}$ & $\begin{array}{l}12 "+\text { T2BS·2RL' } \\
+1 ' 2 B+1 " 5 D\end{array}$ & $62(24.6 \%) \mathrm{b}$ & $21(8.3 \%) \mathrm{a}$ \\
\hline Total & 512 & & $142(27.7 \%)$ & $39(7.6 \%)$ \\
\hline
\end{tabular}

Means with the same letter are not significantly different at $\alpha=5 \%$ using t-test, and means with different letter are significantly different at $\alpha=5 \%$.

Figure 1a:- Crossing scheme using Cappelli phlc mutant.

Durum line

$13 "+$ T2BS $\cdot 2 R L^{\prime}+1 ' 2 B$

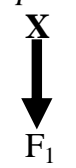

Cappelli $(p h 1 c, p h 1 c)$

$\mathrm{F}_{1}$

Select $F_{1}: 13 "+$ T2BS·2RL'+1'2B $(P h l c, p h l c) \quad$ X Cappelli $(p h l c, p h l c)$

Select $\mathrm{BC}_{1} \mathrm{~F}_{1}: 13 "+$ T2BS·2RL'+1'2B $(p h l c, p h l c) \quad \mathbf{X}$ Cappelli $(p h l c, p h l c)$

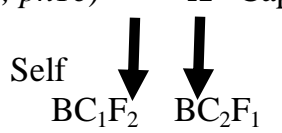

Figure 1b:- Crossing scheme using LDN 5D(5B) disomic substitution lines

Durum line

$13 "+$ T2BS $\cdot 2 R L^{\prime}+1 ' 2 B$
$\underset{\mathbf{X}}{\mathbf{X}} 13^{\prime \prime}+1 " 5 \mathrm{D}$
$\mathrm{F}_{1}$

Select $F_{1}: 12 "$ + T2BS·2RL'+1'2B +1'5B + 1'5D

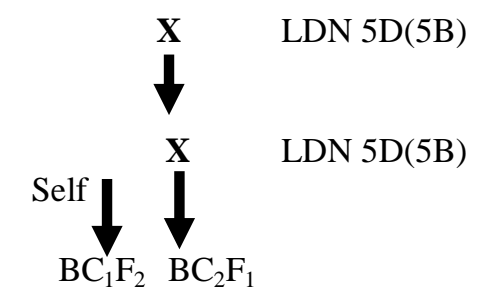

Figure 2:- Metaphase I pairing of T2BS·2RL, GISH pattern of recovered primary recombinants and their reaction to Hessian fly. Rye chromatin is visualized by yellow FITC fluorescence, whereas wheat chromatin is counterstained with PI and fluoresces red. (a) Meiotic metaphase I of T2BS·2RL, the translocated chromosome paired with 2B in the homologous 2BS arm as rod bivalent; insert shows the mitotic GISH pattern of T2BS·2RL; (b) in the absence of $P h 1$, T2BS.2RL pairs with chromosome 2B in the form of a ring bivalent; note homoeologous pairing of 2RL and 2BL; (c) meiotic metaphase I pairing of the primary recombinant rec.\#2 paired in the form of ring bivalent; (d), (e) and (f) GISH pattern of Hessian fly-resistant recombinants (rec.\#1, rec.\#2 and rec.\#3) with about $10 \%$ of the distal part of long arm derived from rye chromatin (T2BS·2BL-2RL); (g) and (h) smallest recombinants (rec.\#4 and rec.\#5) that were susceptible to Hessian fly; (i), (j) and (k) susceptible recombinants (rec.\#6, rec.\#7 and rec.\#8) with about $10 \%$ of the distal part of long arm derived from wheat (T2BS.2RL-2BL); (1) and (m) resistant recombinants rec.\#9 and rec.\#10 with very small distal part of the long arm derived from wheat . 


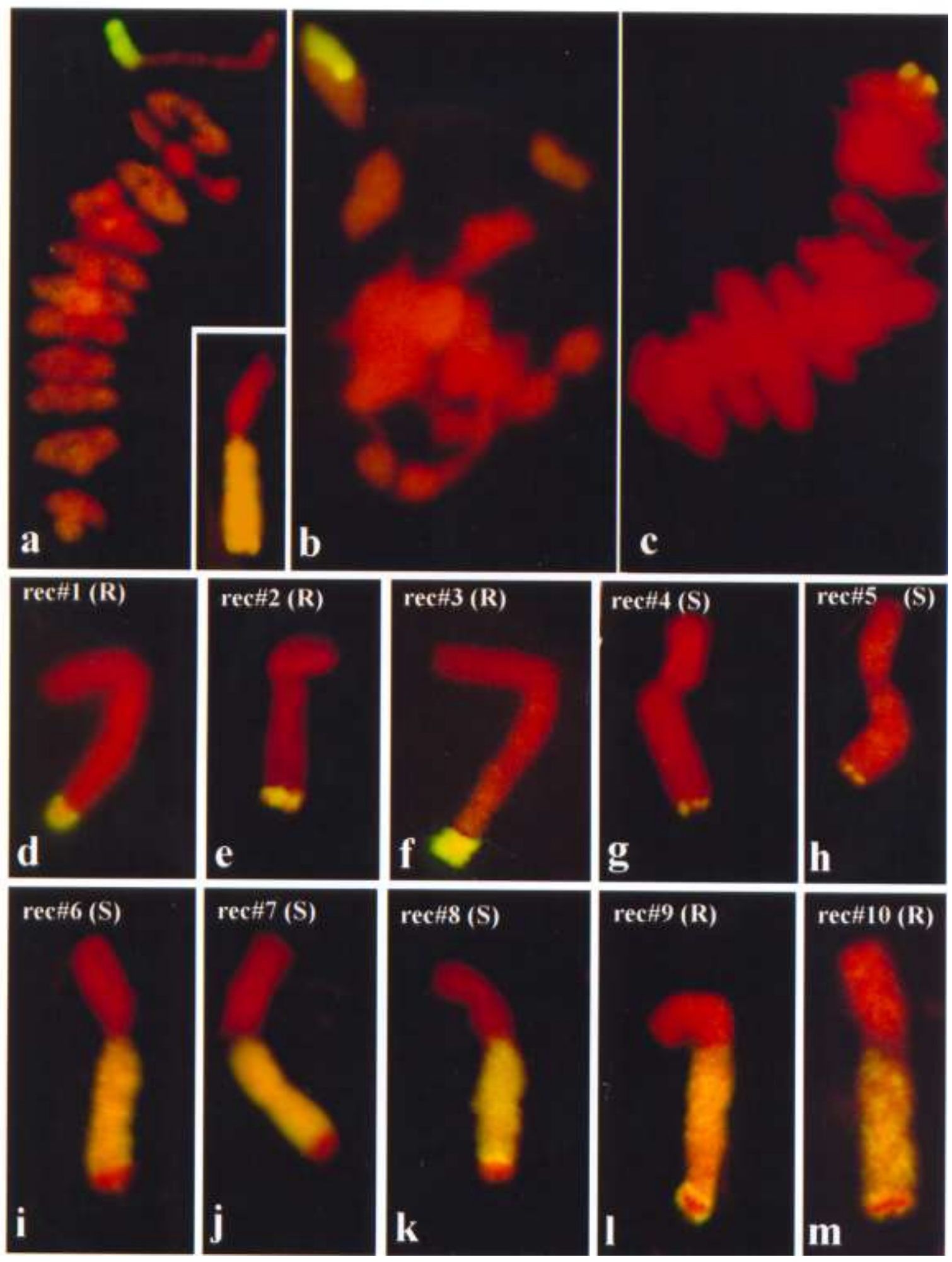




\section{References:-}

1. Aragon-Alcaide, L., S. Reader, A. Beven, P. Shaw, T. Miller, and G. Moore. 1997. Association of homologous chromosomes during floral development. Curr Biol 7: 905-908.

2. Ceoloni, C., M. Biagetti, M. Ciaffi, P. Forte, and M. Pasquiri. 1996. Wheat chromosome engineering at the 4x level: the potential of different alien gene transfers into durum wheat. Euphytica 89: 87-97.

3. Devos, K.M., M.D. Atkinson, C.N. Chinoy, H.A. Francis, R.L. Harcourt, R.M.D. Koebner, C.J. Liu, P. Masojc, D.X. Xie, and M.D. Gale. 1993. Chromosome rearrangements in the rye genome relative to that of wheat. Theor Appl Genet 85: 673-689.

4. Dvorak, J., and A.J. Lukaszewski. 2000. Centromere association is an unlikely mechanism by which the wheat Phl locus regulates metaphase I chromosome pairing between homoeologous chromosomes. Chromosoma 109: 410-414.

5. Dvorak, J., M.M. Noaman, S. Goyal, and J. Gorham. 1994. Enhancement of the salt tolerance of Triticum turgidum L. by the Knal locus transferred from Triticum aestivum L. chromosome 4D by homoeologous recombination. Theor Appl Genet 87: 872-877

6. Dvorak, J., and J. Gorham. 1992. Methodology of gene transfer by homoeologous recombination into Triticum turgidum: transfer of $\mathrm{K}^{+} / \mathrm{Na}^{+}$discrimination from Triticum aestivum. Genome 35: 639-646.

7. El Bouhssini, M., O. Benlahbib, M.M. Nachit, A. Houari, A. Bentika, N. Nsarellah, and S. Lhaloui. 1998. Identification in Aegilops species of resistant sources to Hessian fly (Diptera: Cecidomyiidae) in Morocco. Genetic Resources and Crop Evolution 45: 343-345.

8. Feldman, M. 1993. Cytogenetic activity and mode of action of the pairing homoeologous $(P h 1)$ gene of wheat. Crop Sci 33: 894-897.

9. Friebe, B., J.H. Hatchett, R.G. Sears, and B.S. Gill. 1990. Transfer of Hessian fly resistance from 'Chaupon' rye to hexaploid wheat via a T2BS·2RL wheat-rye chromosome translocation. Theor Appl Genet 79: 385-389.

10. Friebe, B., J.H. Hatchett, B.S. Gill, Y. Mukai, and E.E. Sebesta. 1991. Transfer of Hessian fly resistance from rye to wheat via radiation-induced terminal and intercalary chromosomal translocations. Theor Appl Genet 83: 33-40.

11. Friebe, B., M. Heun, N. Tuleen, F.J. Zeller, and B.S. Gill. 1994. Cytogenetically monitored transfer of powdery mildew resistance from rye into wheat. Crop Sci. 34: 621-625.

12. Friebe, B., J. Jiang, W.J. Raupp, R.A. McIntosh, and B.S. Gill. 1996. Characterization of wheat-alien translocations conferring resistance to diseases and pests: current status. Euphytica 91: 59-87.

13. Friebe, B., R.G. Kynast, J.H. Hatchett, R.G. Sears, D.L. Wilson, and B.S. Gill. 1999. Transfer of wheat-rye translocation chromosomes conferring resistance to Hessian fly from bread wheat into durum wheat. Crop Sci 39: 1692-1696.

14. Gill, B.S., B. Friebe, and T.R. Endo. 1991. Standard Karyotype and nomenclature system for description of chromosome bands and structural aberrations in wheat (Triticum aestivum). Genome 34: 830-839.

15. Gill, K.S., and B.S. Gill. 1994. Mapping in the realm of polyploidy: The wheat model. BioEssays vol. 16, No.11: 841-846.

16. Giorgi, B. 1978. A homoeologous pairing mutant isolated in Triticum durum Cv. Cappelli. Mutat. Breed. Newsletter. 11: 4-5.

17. Hatchett, J.H., and R.L. Gallun. 1970. Genetics of the ability of the Hessian fly, Mayetiola destructor, to survive on wheats having different genes for resistance. Ann Entomol Soc Am 63: 1400-1407.

18. Hatchett, J.H., T.J. Martin, and R.W. Livers. 1981. Expression and inheritance of resistance to Hessian fly in synthetic hexaploid wheats derived from Triticum tauschii (Coss) Schmal. Crop Sci 21: 731-734.

19. Jauhar, P.P., O. Riera-Lizarazu, W.G. Dewey, B.S. Gill, C.F. Crane, and J.H. Bennett. 1991. Chromosome pairing relationships among the A, B, and D genomes of bread wheat. Theor Appl Genet 82: 441-449.

20. Jauhar, P.P., A.B. Almouslem, T.S. Peterson, and L.R. Joppa. 1999. Inter- and intragenomic chromosome pairing in haploids of durum wheat. Hered. 90(4): 437-445.

21. Jiang, J., B. Friebe, and B.S. Gill. 1994a. Chromosome painting of Amigo wheat. Theor Appl Genet 89: 811813.

22. Jiang, J., B. Friebe, and B.S. Gill. 1994b. Recent advances in alien gene transfer in wheat. Euphytica 73: 199212.

23. Joppa, L.R. 1993. Chromosome engineering in tetraploid wheat. Crop Sci 33(5): 908-913.

24. Kimber, G., and R. Riley. 1963. The relationships of the diploid progenitors of hexaploid wheat. Can J Genet Cytol 5: 83-88. 
25. Lhaloui, S., M. El Bouhssini, M.M. Nachit, N. Nsarellah, and A. Amri. 1998. New sources of resistance to Hessian fly in Wheat in Morocco. Vol. 3: 287-289. In A.E. Slinkard (ed.) Proc Intl Wheat Genet Symp, $9^{\text {th }}$. Saskatoon, SK. University Extension Press, University of Saskatchewan, Saskatoon.

26. Lukaszewski, A.J. 1993. Reconstruction of complete chromosomes $1 \mathrm{~B}$ and 1R from the 1RS.1BL translocation of 'Kavkaz' origin. Genome 36: 821-824.

27. Lukaszewski, A.J. 1995. Physical distribution of translocation breakpoints in homoeologous recombinants induced by the absence of the Phl gene in wheat and triticale. Theor Appl Genet 90: 714-719.

28. Lukaszewski, A.J. 1997. Further manipulation by centric misdivision of the 1RS.1BL translocation in wheat. Euphytica 94: 257-261.

29. Lukaszewski, A.J. 2000. Manipulation of the 1RS.1BL translocation in wheat by induced homoeologous recombination. Crop Sci 40: 216-225.

30. Luo, M-C, Dubcovsky, and J. Dvorak. 1996a. Recognition of homoeology by the Phl locus. Genetics 143: 1195-1203.

31. Luo, M-C, Dubcovsky, S. Goyal, and J. Dvorak. 1996b. Engineering of interstitial foreign chromosome segments containing the $\mathrm{K}^{+} / \mathrm{Na}^{+}$selectivity gene Knal by sequential homoeologous recombination in durum wheat. Theor Appl Genet 93: 1180-1184.

32. Martinez M., T. Naranjo, C. Cuadrado, and C. Romero. 2001. The synaptic behavior of Triticum turgidum with variable doses of the Phl locus. Theor Appl Genet 102: 751-758.

33. Martines-Perez E., P. Shaw, S. Reader, L. Aragon-Alcaide, T. Miller, and G. Moore. 1999. Homologous chromosome pairing in wheat. J Cell Sci 112: 1761-1769.

34. McIntosh, R.A., G.E. Hart, K.M. Devos, M.D. Gale, and W.J. Rogers. 1998. Catalogue of gene symbols for wheat. Vol. 5: 1-236. In A.E. Slinkard (ed.) Proc Intl Wheat Genet Symp, $9^{\text {th }}$. Saskatoon, SK. University Extension Press, University of Saskatchewan, Saskatoon.

35. Mikhailova, E.I., T. Naranjo, K. Shephered, J. Wennekes-van Eden, C. Heyting, and H. de Jong. 1998. The effect of wheat Phl locus on chromatin organization and meiotic pairing analyzed by genome pairing. Chromosoma 107: 339-350.

36. Naranjo, T., P. Fernandez-Rueda. 1996. Pairing and recombination between individual chromosomes of wheat and rye in hybrids carrying the $p h l b$ mutation. Theor Appl Genet 93: 242-248.

37. Nsarellah, N., M.M. Nachit, M. El Bouhssini, S. Lhaloui, and A. Amri. 1998. Introgression of Hessian fly resistance into durum wheat in Morocco. Vol. 3: 303-304. In A.E. Slinkard (ed.) Proc Intl Wheat Genet Symp, $9^{\text {th }}$. Saskatoon, SK. University Extension Press, University of Saskatchewan, Saskatoon.

38. Okamoto, M. 1957. Asynaptic effect of chromosome V. Wheat Info Service 5:6.

39. Ratcliffe, R.H., and J.H. Hatchett. 1997. Biology and genetics of the Hessian fly and resistance in wheat. New developments in Entomology, pp: 47-55.

40. Riley, R., and V. Chapman. 1958. Genetic control of the cytologically diploid behavior of hexaploid wheat. Nature 182: 713-715.

41. Riley, R., V. Chapman, and R. Johnson. 1968a. The incorporation of alien disease resistance in wheat by genetic interference with the regulation of meiotic chromosome synapsis. Genet Res 12: 199-219.

42. Riley, R., V. Chapman, and R. Johnson. 1968b. Introduction of yellow rust resistance of Aegilops comosa into wheat by genetically induced homoeologous recombination. Nature 217: 383-384.

43. Roberts, M.A., S.M. Reader, C. Dalgliesh, T.E. Miller, T.N. Foote, L.J. Fish, J.W. Snape, and G. Moore. 1999. Induction and characterization of Phl wheat mutants. Genetics 153: 1909-1918.

44. Sears, E.R. 1976. Genetic control of chromosome pairing in wheat. Ann Rev Genet 10: 31-51.

45. Sears, E.R. 1977. An induced mutant with homoeologous pairing in common wheat. Can J Genet Cytol 19: 585593.

46. Sears, E.R. 1993. Use of radiation to transfer alien segments to wheat. Crop Sci 32: 897-901. 